\title{
Molybdenum isotope fractionations observed under anoxic experimental conditions
}

\author{
Rebecca L. Poulson Brucker, ${ }^{1}$ James McManus $^{1 *}$ and Simon W. Poulton ${ }^{2}$ \\ ${ }^{1}$ Oregon State University, College of Oceanic and Atmospheric Sciences, Corvallis, OR 97331-5503, U.S.A. \\ ${ }^{2}$ School of Civil Engineering and Geosciences, Newcastle University, Newcastle upon Tyne, NE1 7RU, England, U.K.
}

(Received October 13, 2011; Accepted March 2, 2012)

\begin{abstract}
Experiments were carried out to determine molybdenum isotope fractionation associated with adsorption to pyrite. Results show that the Mo isotope composition of the aqueous solution becomes progressively heavier as Mo is adsorbed, with a Mo isotope fractionation as large as $2.9 \%$. This fractionation is larger than observed for typical anoxic continental margin marine sediments (e.g., $\sim 0.7 \%$ ), suggesting that Mo adsorption to pyrite is not the dominant process operating in these environments. However, our adsorption results do suggest the possibility that anoxic fractionation processes could impart an isotope signature within the geologic record similar to the isotope fractionation observed under oxygenated conditions. Additional experiments were conducted at high $(\sim 100 \mu \mathrm{M})$ dissolved Mo concentrations, but at varying pH and $\Sigma \mathrm{H}_{2} \mathrm{~S}$ concentrations, and in each case these experiments promoted Mo-sulfide precipitation. Even though the experiments were conducted under differing conditions and produced different amounts of precipitate, the results suggest a constant fractionation of $\sim 0.9 \%$ associated with this Mo removal process. This fractionation is more consistent with that inferred for anoxic continental margin marine sediments, suggesting that a process similar to Mo-sulfide precipitation, rather than an adsorption process, may be responsible for the Mo isotope compositions observed in these environments. The findings of this study suggest that, regardless of the geochemical mechanism employed, sediment Mo sequestration under anoxic conditions may impart a significant isotopic fractionation relative to parent seawater.
\end{abstract}

Keywords: molybdenum, isotopes, diagenesis, sediments

\section{INTRODUCTION}

Molybdenum is an element that has received attention as a tracer for ancient Earth chemistry (e.g., Algeo and Lyons, 2006; Tribovillard et al., 2006; Anbar and Rouxel, 2007; Scott et al., 2008, 2011; Lyons et al., 2009). This interest has been sparked, in part, because Mo changes solubility with the respective presence or absence of sulfide (e.g., Helz et al., 1996), and because differing oxidation-reduction conditions appear to impart distinctive Mo isotopic fractionations (e.g., Anbar and Rouxel, 2007; Poulson Brucker et al., 2009). Sulfide concentrations control Mo speciation in anoxic environments, with the dominant dissolved Mo phase transitioning from molybdate $\left(\mathrm{MoO}_{4}{ }^{2-}\right)$ to tetrathiomolybdate $\left(\mathrm{MoS}_{4}{ }^{2-}\right)$ at a sulfide-controlled geochemical action point switch (APS) of $\sim 11 \mu \mathrm{M} \mathrm{H}_{2} \mathrm{~S}_{(\mathrm{aq})}$ (Helz et al., 1996, 2004; Erickson and Helz, 2000). At sulfide concentrations below the APS, thiomolybdate intermediates $\left(\mathrm{MoO}_{x} \mathrm{~S}_{4-x}{ }^{2-}\right)$ may be scavenged by organic matter or solid sulfide phases (Helz et

*Corresponding author (e-mail: mcmanus@coas.oregonstate.edu)

Copyright $@ 2012$ by The Geochemical Society of Japan. al., 1996, 2004; Zheng et al., 2000; Algeo and Lyons, 2006; Tribovillard et al., 2004, 2006), and formation or subsequent removal of these intermediates may be one way of driving variations in Mo isotope fractionation under reducing conditions (Neubert et al., 2008).

In the open ocean, which is generally devoid of dissolved sulfide, Mo is primarily present as molybdate $\left(\mathrm{MoO}_{4}{ }^{2-}\right.$; e.g., Emerson and Huested, 1991). Here seawater Mo concentrations are relatively high $(\sim 105 \mathrm{nM})$ and quasi-uniform (Collier, 1985; Fig. 1A), and the modern seawater Mo isotope composition also appears to be reasonably uniform as well (Barling et al., 2001; Siebert et al., 2003). In well-oxygenated sediments of the open ocean, Mo is primarily associated with solid-phase Mn and Fe-oxides (e.g., Bertine and Turekian, 1973; Calvert and Pedersen, 1993; Chappaz et al., 2008). Experimental work and natural samples have shown that Mo adsorption to Mn-oxides results in sediment Mo isotope values that are fractionated relative to parent seawater Mo (Barling et al., 2001; Siebert et al., 2003, 2006; Barling and Anbar, 2004; Wasylenki et al., 2008; Poulson Brucker et al., 2009; Figs. 1B and C). The process responsible for this particular fractionation appears to be related to a change in coordination from tetrahedral to octahedral (e.g., Wasylenki et al., 2011; Kashiwabara et al., 2011). 


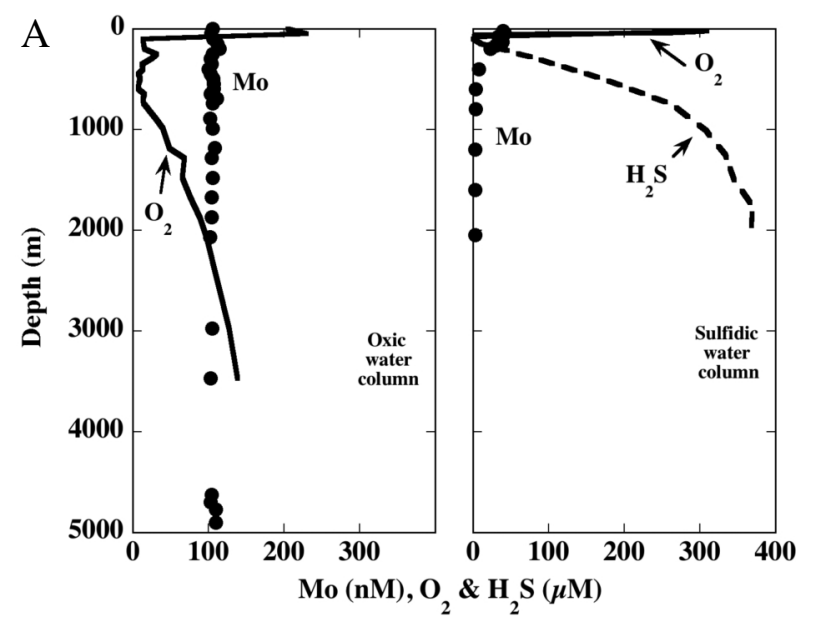

B
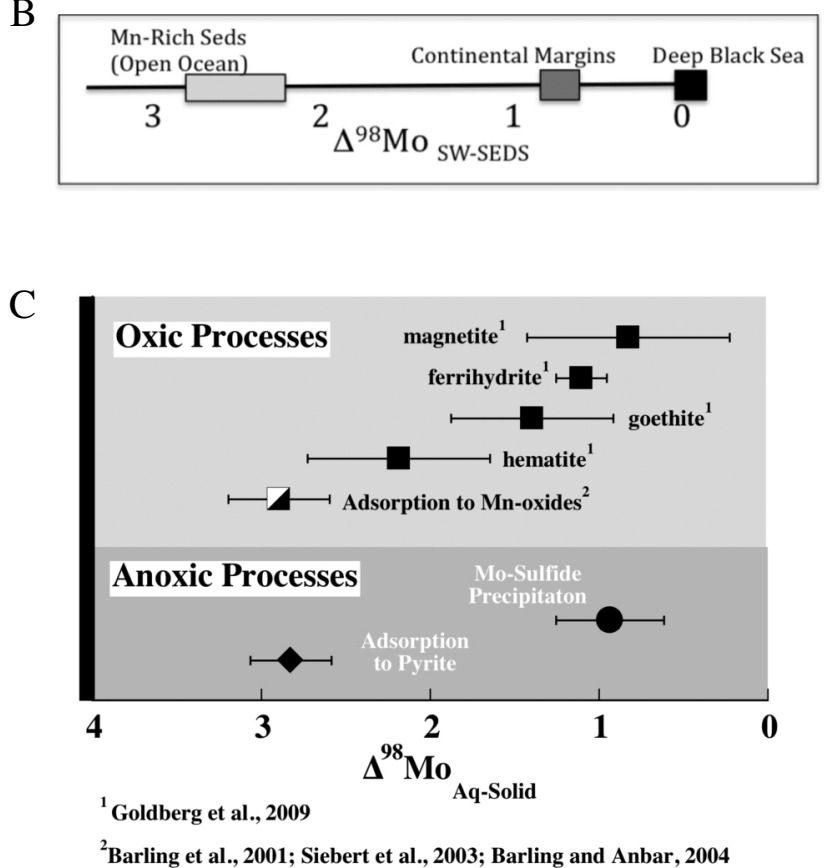

Fig. 1. (A) Dissolved Mo, oxygen, and $\mathrm{\Sigma}_{2} \mathrm{~S}$ as a function of water depth from the central Pacific (left) and the Black Sea (right). Both the Pacific Mo and oxygen data were supplied by Robert Collier (OSU) and the Mo data were previously published (Collier, 1985). The Black Sea Mo data were tabulated in Dyrssen (1999), which were taken from Emerson and Huested (1991). Black Sea sulfide data were taken from Neretin et al. (2001) and the oxygen data from Colodner (1991). (B) Schematic depicting Mo isotope offsets from parent seawater from three typical environmental settings. (C) Experimental fractionation of Mo under oxic (top) and anoxic conditions. Here "oxic processes" represent Mo adsorption to iron and manganese oxides (after Barling et al., 2001; Siebert et al., 2003; Barling and Anbar, 2004; Goldberg et al., 2009). Anoxic processes refer to those determined in this study and error bars represent are $2 \sigma$.
In contrast, under the highly-sulfidic conditions ( $>10$ $\mu \mathrm{M} \mathrm{H}_{2} \mathrm{~S}_{[\mathrm{aq}]}$ ) of the restricted Black Sea, near-complete water column Mo removal is apparent (Emerson and Huested, 1991; Nägler et al., 2011; Fig. 1A). In the deep Black Sea the sulfide APS for Mo is met in the water column, and sediments record a Mo isotope composition analytically indistinguishable from that of seawater (Arnold et al., 2004; Neubert et al., 2008; Fig. 1B). However, euxinic environments like the Black Sea where high concentrations of sulfide are present in the overlying water column are relatively rare in the modern ocean, and the predominant anoxic sedimentary sink for Mo in the modern ocean likely comprises a variety of other continental margin environments (e.g., McManus et al., 2006).

In continental margin settings, high biological productivity can intensify water column oxygen minimum zones (OMZs, e.g., Diaz and Rosenberg, 2008) and sediments underlying OMZs experience reducing conditions, though detectable sulfide is typically limited to sediment pore fluids (e.g., Fossing, 1990). Sediment Mo isotope compositions from these anoxic (but non-euxinic) settings suggest that fractionation occurs between anoxic authigenic sedimentary Mo deposits and seawater Mo (Fig. 1B), though this fractionation can be quite variable, and the controlling geochemical mechanisms remain somewhat vague (e.g., Neubert et al., 2008; Poulson Brucker et al., 2009).

The importance of the Fe cycle as an additional control on anoxic sediment Mo fractionation, through interactions with either pyrite or iron oxides, is particularly noteworthy as Mo is thought to interact with these phases (Huerta-Diaz and Morse, 1992; Helz et al., 1996, 2004; Zheng et al., 2000; Goldberg et al., 2009, 2012; Kashiwabara et al., 2009). Experimental investigations of molybdate adsorption to $\mathrm{Fe}-$ oxides generated a range of Mo isotope fractionations, from 0.8 to $2.2 \%$ depending upon the $\mathrm{Fe}-$ oxide mineralogy (Goldberg et al., 2009; Fig. 1C). This range of values is similar to the range observed in manganous, ferruginous, and sulfidic (terminology from Canfield and Thamdrup, 2009) marine sediments (Siebert et al., 2006, Poulson et al., 2006, Poulson Brucker et al., 2009), which raises the possibility that $\mathrm{Fe}$-oxide cycling may influence Mo isotope behavior in these settings as well.

Notwithstanding the potential role of Mo adsorption to iron oxides in reducing continental margin settings, the dominant processes influencing Mo burial in such environments are thought to reflect diagenetic reactions among Mo, reduced sulfur phases, and iron (e.g., HuertaDiaz and Morse, 1992). This makes sense in that iron and sulfur oxidation-reduction reactions are common early diagenetic processes in continental margin sediments (e.g., Severmann et al., 2010). Observations from black shales suggest that pyrite $\left(\mathrm{FeS}_{2}\right)$ is the most important 
host-phase for Mo in anoxic sediments (Huerta-Diaz and Morse, 1992). Furthermore, laboratory experiments have demonstrated sorption of Mo-sulfides to pyrite, and this sorption results in the formation of a Mo-Fe-S cubane structure (Helz et al., 1996; Bostick et al., 2003; Vorlicek et al., 2004; Xu et al., 2006). Because cubane formation alters the bonding environment around the Mo atom (Bostick et al., 2003), this process might be expected to fractionate Mo isotopes.

This study presents anoxic laboratory experiments investigating Mo isotope fractionations associated with both Mo adsorption to pyrite and Mo-sulfide precipitation. Our approach builds upon similar anoxic Mo experimental investigations (Bostick et al., 2003; Xu et al., 2006) by adding Mo isotope measurements, thereby providing new constraints on the mechanisms associated with the sequestration and isotope fractionation of Mo in anoxic continental margin sediments.

\section{EXPERIMENTAL METHODS}

\section{Experimental conditions}

The parameters for our initial adsorption experiment (indicated as Experiment Series A, Table 1) were selected to simulate natural conditions in reducing marine sediments to the extent analytically feasible. The starting aqueous molybdenum solution was $\sim 300 \mathrm{nM}$, which is roughly three times the Mo concentration typically measured in seawater (Collier, 1985). The experiment was conducted at a $\mathrm{pH}$ of 6.5 because the $\mathrm{pH}$ of anoxic pore fluids is generally self-buffered at $\sim 6.6$, owing to reactions between the sulfide produced via sulfate reduction and the carbonate present in ambient seawater (Burdige, 2006). To maximize Mo adsorption no additional aqueous sulfide was added in this experiment, as previous work has suggested that sulfide outcompetes Mo for available sorption sites on pyrite (Bostick et al., 2003).

Four additional experiments (Experiment Series 1-4, Table 1) were conducted at $\sim 100 \mu \mathrm{M}$ Mo. We selected this increase in aqueous Mo concentration for ease of analytical measurements, and to reproduce the concentrations of similar previous pyrite sorption experiments (Xu et al., 2006; Bostick et al., 2003). For Experiment Series 1 and 2 (conducted at $\mathrm{pH} 4.1$ and 6.0 respectively), no sulfide was added, whereas Experiment Series 3 and 4 (conducted at similar $\mathrm{pH}$ values of 4.0 and 6.5 respectively) were performed in the presence of dissolved sulfide (400 and $700 \mu \mathrm{M}$ sulfide respectively; Table 1).

\section{Aqueous $\mathrm{MoS}_{4}$ solutions}

The primary aqueous Mo solutions for all experimental runs were prepared in an air-tight glass vessel equipped with gas-tight ports for $\mathrm{pH}$ maintenance (electrode and deoxygenated $\mathrm{HCl}$ input), degassing (nitrogen inlet and outlet), and sample addition or removal (e.g., see Poulton, 2003). All experiments were run at an ionic strength of $0.005 \mathrm{M}(\mathrm{NaCl})$, stirred constantly, and held at a temperature of $25^{\circ} \mathrm{C}$ using a water bath. The desired initial aqueous $\mathrm{MoS}_{4}$ concentrations were achieved through the addition of $\left(\mathrm{NH}_{4}\right)_{2} \mathrm{MoS}_{4}$ salt to $18 \mathrm{M} \Omega \mathrm{H}_{2} \mathrm{O}$ (Table 1). Solutions were degassed with ultra-pure nitrogen (99.999\%), which was further purified by passing through an Alltech oxygen trap and an Alltech indicating oxygen trap for at least 1 hour prior to sampling or sulfide addition. Initial solution $\mathrm{pH}$ was raised either through sulfide (added as $\mathrm{Na}_{2} \mathrm{~S} \cdot 9 \mathrm{H}_{2} \mathrm{O}$ ) or dilute $\mathrm{NaOH}$ addition (Table 1 ); all other $\mathrm{pH}$ adjustments were made through the addition of deoxygenated $\mathrm{HCl}$ (Table 1) as necessary (controlled via a $\mathrm{pH}$-stat), and no $\mathrm{pH}$ buffers were used. All acids used in the experimental series, sample preparation, and sample analyses were trace metal clean; ultrapure used as purchased, or distilled in-house.

\section{Pyrite suspensions}

Aliquots $(50 \mathrm{ml})$ were extracted from the bulk $\mathrm{MoS}_{4}$ solution using an airtight syringe and immediately injected into nitrogen-purged glass bottles $(150 \mathrm{ml})$ containing preweighed amounts of pre-washed synthetic pyrite $\left(\mathrm{FeS}_{2}\right.$, Strem Chemical, Table 1). This particular synthetic pyrite was selected because it is from the same manufacturer as the material used in similar previously published sorption experiments (Bostick et al., 2003; Xu et al., 2006). The pyrite was washed with water, $0.1 \mathrm{M} \mathrm{HCl}$, and $0.01 \mathrm{M}$ sulfide to remove oxidized surface species prior to use, then freeze-dried and stored in the freezer. Surface area was not measured in this study, but Bostick et al. (2003) report a surface area of $41.7 \mathrm{~m}^{2} / \mathrm{g}$ for pyrite from the same manufacturer treated with the same cleaning procedure.

The suspensions were allowed to react on a shaker table for at least 7 hours to reach adsorption equilibrium (Xu et al., 2006). Pyrite was then filtered from all suspensions through $0.2 \mu \mathrm{m}$ PTFE syringe filters, and solutions were stored unfrozen in pre-washed LDPE bottles (with Parafilm banding around the lids for additional deterrence of oxygen penetration) for transport and further analysis. The pyrite fractions were collected and stored on the filter cartridges.

\section{Mo analyses}

The Mo concentrations of all aqueous filtered solutions were determined directly by inductively-coupled plasma mass spectrometry (ICPMS, Thermo PQ ExCell; Supplementary Table 1). Samples were diluted as necessary to achieve $\sim 30 \mathrm{ng}$ Mo sample sizes for analysis. Replicate ICPMS analyses were performed on $\sim 40 \%$ of all experimental samples in this study, and measured Mo concentrations were on average reproducible to within 
Table 1. Experimental conditions and results

\begin{tabular}{|c|c|c|c|c|c|c|c|c|c|c|c|}
\hline & $\begin{array}{c}\text { Calculated initial } \\
\mathrm{Mo}_{\mathrm{aq}}(\mu \mathrm{M})\end{array}$ & $\begin{array}{l}\text { Initial sulfide } \\
\quad(\mu \mathrm{M})\end{array}$ & $\mathrm{pH}$ & $\begin{array}{c}0.01 \mathrm{M} \mathrm{NaOH} \\
(\mathrm{ml})\end{array}$ & $\begin{array}{l}10 \% \mathrm{HCl} \\
(\mathrm{ml})\end{array}$ & $\begin{array}{l}\text { Pyrite } \\
(\mathrm{g} / \mathrm{L})\end{array}$ & $\begin{array}{c}\mathrm{AVG} \mathrm{Mo} \\
(\mu \mathrm{M})\end{array}$ & $\pm 2 \mathrm{SD}$ & $\%$ Mo Lost & $\begin{array}{c}\mathrm{AVG} \mathrm{Mo} \\
\delta^{98} \mathrm{Mo}\end{array}$ & $\pm 2 \mathrm{SD}$ \\
\hline \multicolumn{12}{|c|}{ Experiment Series A } \\
\hline A-START & 0.26 & 0 & 6.5 & 13.8 & 0.01 & & 0.30 & 0.02 & & -0.1 & 0.1 \\
\hline A1 & & & & & & 0.2 & 0.29 & 0.02 & 4 & 0.0 & \\
\hline A2 & & & & & & 0.5 & 0.28 & 0.04 & 9 & 0.1 & 0.2 \\
\hline A3 & & & & & & 1.0 & 0.24 & 0.07 & 19 & 0.4 & 0.0 \\
\hline A4 & & & & & & 1.5 & 0.23 & 0.08 & 24 & 0.6 & \\
\hline A5 & & & & & & 3.1 & 0.11 & & 64 & & \\
\hline \multicolumn{12}{|c|}{ Experiment Series 1} \\
\hline 1 START & 99.1 & 0 & 4.1 & 0.0 & 0.03 & & 56 & 7 & 43 & 0.2 & 0.2 \\
\hline $1 \mathrm{~A}$ & & & & & & 1.0 & 47 & 3 & 53 & 0.5 & 0.0 \\
\hline 1B & & & & & & 1.0 & 52 & 4 & 48 & 0.4 & 0.0 \\
\hline $1 \mathrm{C}$ & & & & & & 5.1 & 46 & 4 & 53 & 0.3 & \\
\hline 1D & & & & & & 5.1 & 47 & 5 & 53 & 0.2 & 0.1 \\
\hline $1 \mathrm{E}$ & & & & & & 9.9 & 41 & 4 & 59 & 0.3 & \\
\hline $1 \mathrm{~F}$ & & & & & & 9.9 & 43 & 0 & 57 & 0.4 & 0.1 \\
\hline \multicolumn{12}{|c|}{ Experiment Series 2} \\
\hline 2 START & 102.2 & 0 & 6.0 & 7.9 & 0.04 & & 84 & 5 & 17 & 0.1 & \\
\hline $2 \mathrm{~A}$ & & & & & & 1.0 & 85 & 1 & 17 & -0.0 & \\
\hline $2 \mathrm{~B}$ & & & & & & 1.0 & 83 & 1 & 19 & -0.1 & \\
\hline $2 \mathrm{C}$ & & & & & & 2.0 & 85 & 7 & 16 & -0.0 & \\
\hline $2 \mathrm{D}$ & & & & & & 2.0 & 90 & 22 & 12 & -0.1 & 0.2 \\
\hline $2 \mathrm{E}$ & & & & & & 3.0 & 84 & & 18 & 0.0 & \\
\hline $2 \mathrm{~F}$ & & & & & & 3.0 & 72 & 23 & 29 & 0.2 & \\
\hline \multicolumn{12}{|c|}{ Experiment Series 3} \\
\hline 3 START & 102.6 & $\sim 400$ & 4.0 & 0.0 & 0.22 & & 42 & 17 & 59 & 0.5 & 0.2 \\
\hline $3 \mathrm{~A}$ & & & & & & 1.0 & 22 & 7 & 79 & 1.1 & 0.2 \\
\hline $3 \mathrm{~B}$ & & & & & & 1.0 & 26 & 17 & 75 & 1.3 & \\
\hline $3 \mathrm{C}$ & & & & & & 2.0 & 23 & 12 & 77 & 1.4 & \\
\hline $3 \mathrm{D}$ & & & & & & 2.0 & 23 & 10 & 78 & 1.3 & 0.3 \\
\hline $3 \mathrm{E}$ & & & & & & 3.0 & 22 & 12 & 78 & 1.4 & \\
\hline $3 \mathrm{~F}$ & & & & & & 3.0 & 23 & 10 & 77 & 1.1 & 0.3 \\
\hline \multicolumn{12}{|c|}{ Experiment Series 4} \\
\hline 4 START & 98.4 & $\sim 700$ & 6.5 & 0.0 & 0.25 & & 82 & 7 & 17 & 0.0 & \\
\hline $4 \mathrm{~A}$ & & & & & & 1.0 & 86 & 8 & 12 & -0.0 & \\
\hline $4 \mathrm{~B}$ & & & & & & 0.9 & 86 & 6 & 12 & -0.1 & \\
\hline $4 \mathrm{C}$ & & & & & & 2.1 & 91 & 15 & 8 & -0.0 & 0.5 \\
\hline $4 \mathrm{D}$ & & & & & & 1.9 & 86 & 5 & 12 & -0.0 & \\
\hline $4 \mathrm{E}$ & & & & & & 2.9 & 86 & 5 & 13 & -0.1 & \\
\hline $4 \mathrm{~F}$ & & & & & & 3.0 & 94 & 11 & 4 & -0.1 & \\
\hline
\end{tabular}

Calculated Initial $\mathrm{Mo}_{\text {aq }}$ concentrations from known quantities of $\left(\mathrm{NH}_{4}\right)_{2} \mathrm{MoS}_{4}$ salt added at the start of each experiment. Initial sulfide values from known quantities of stock $200 \mathrm{mM} \mathrm{H}_{2} \mathrm{~S}$ solution added at the start of each experiment. All initial pH values determined using a digital readout $\mathrm{pH}$ stat; for Experiments $\mathrm{A}$ and 2, dilute $\mathrm{NaOH}$ was added to raise the initial $\mathrm{pH}$ to $\sim 6$ (without sulfide addition) and all other pH adjustments were made through the addition of deoxygenated $\mathrm{HCl}$ as necessary. Average Mo aq values listed for all experimental samples represent the average of separate aliquots analyzed by both ICPMS and MC-ICPMS (except sample A5); see Supplementary Table 1. For Experiment Series A, \% Mo Lost is calculated as the difference between the measured aqueous Mo concentration of the sample and the measured Mo concentration of the experimental starting solution. For Experiment Series 1-4, \% Mo Lost is calculated as the difference between the measured aqueous Mo concentration of the sample and the calculated initial solution Mo concentration based on the amount of salt initially added. Average $\delta^{98}$ Mo values represent the average of multiple separate sample runs (when 2-SD error is present; see Supplementary Table 2) Samples with no errors for Mo isotope values were only run once.

$\sim 10 \%$ (2-SD; Supplementary Table 1).

Additional sample aliquots from the experimental LDPE sample bottles were spiked with a ${ }^{97} \mathrm{Mo}-{ }^{100} \mathrm{Mo}$ double-spike solution and pre-concentrated by ion exchange chromatography for Mo isotope analysis following previously published techniques (Siebert et al., 2001,
2006). Mo isotope compositions and concentrations were determined using a $N u$ Instruments $H R$ multi-collector inductively-coupled plasma mass spectrometer (MCICPMS; Supplementary Tables 1 and 2). All Mo isotope measurements are reported relative to a Claritas $P P T$ ICPMS Mo standard solution (Lot \#CL2-44MO; $\delta^{98} \mathrm{Mo}$ 
$\left.\left.=\left[{ }^{98 / 95} \mathrm{Mo}_{\text {SAMPLE }}{ }^{98 / 95} \mathrm{Mo}_{\text {STANDARD }}-1\right] \times 1000\right)\right)$.

To assess the reproducibility of our technique, we performed replicate MC-ICPMS analyses of a $10 \mathrm{ppm}$ (104 $\mu \mathrm{M})$ Mo standard solution (Claritas PPT ICPMS Mo Standard, Lot \#CL2-44MO, Supplementary Table 3), double-spiked and preconcentrated as described for experimental samples. The long-term average measured Mo concentration was $107 \pm 13 \mu \mathrm{M}(2-\mathrm{SD}, n=14$, Supplementary Table 1). The reproducibility of individual ${ }^{98} \mathrm{Mo} /$ ${ }^{95}$ Mo ratios is typically at or below $0.1 \%$ ( $\left.2 \sigma\right)$ from inrun statistics (Supplementary Table 3), and the long-term average isotope composition for the $10 \mathrm{ppm}$ Mo standard was $\delta^{98} \mathrm{Mo}=0.0 \pm 0.2 \%$ (2-SD, $n=17$, Supplementary Table 3). Replicate MC-ICPMS analyses were performed on $\sim 40 \%$ of all experimental samples in this study, and the reproducibility of sample Mo isotope compositions was generally consistent with that of our standard solution, on average within $\pm 0.2 \%$ o (2-SD; Supplementary Table 2). For those same replicates, measured Mo concentrations were on average reproducible to within $\sim 6 \%$ (2-SD; Supplementary Table 1). The Mo concentrations of all experimental samples listed in Table 1 represent the average of separate aliquots of the same samples analyzed by both ICPMS and MC-ICPMS (except sample A5, Supplementary Table 1).

\section{RESULTS}

\section{Mo adsorption to pyrite}

The measured Mo concentration at the start of Experiment Series A (labeled "A-Start" in Table 1) was $301 \mathrm{nM}$ (Table 1). This value is consistent with the calculated initial Mo solution concentration (259 nM, Table 1), suggesting at most a $0.0004 \mathrm{~g}$ error in the quantity of $\left(\mathrm{NH}_{4}\right)_{2} \mathrm{MoS}_{4}$ salt initially added to the bulk $1 \mathrm{~L}$ Mo experimental solution. For each pyrite-reacted experimental sample (A1-A5), the Mo lost from solution was calculated as the difference between the measured sample Mo concentration and that measured in the initial starting solution (Table 1). The aqueous Mo concentrations of the reacted samples suggest sorption of Mo is a function of pyrite suspension density, with a dissolved Mo uptake of $\sim 60 \mathrm{nmol} / \mathrm{g}$ pyrite (Fig. 2A). As much as $64 \%$ of the available aqueous Mo appears to have adsorbed to the pyrite during the 24-hour suspension reaction time (Table 1). This experimental series may be pyritelimited; that is, the extent of Mo sorption may be limited by the number of available reactive surface sites on pyrite, which itself is a function of the surface area supplied in each experiment.

The initial solution Mo isotope composition is $\delta^{98} \mathrm{Mo}_{\mathrm{aq}}$ $=-0.1 \%$, but the Mo isotope composition of the aqueous solution becomes progressively heavier as more Mo is lost from solution (due to the small quantity of Mo, sam-
(A)

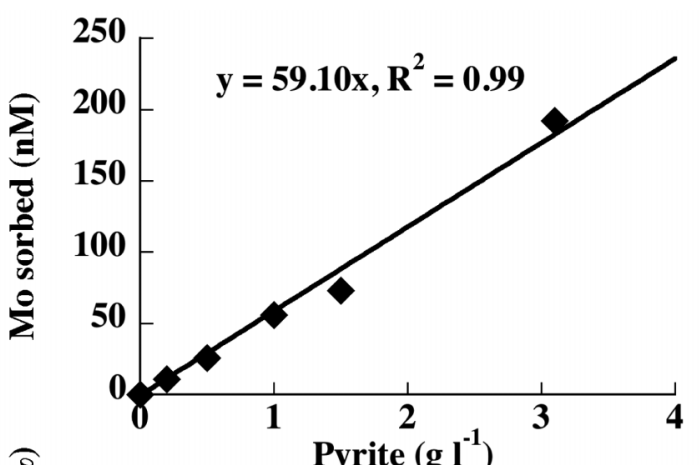

(B)

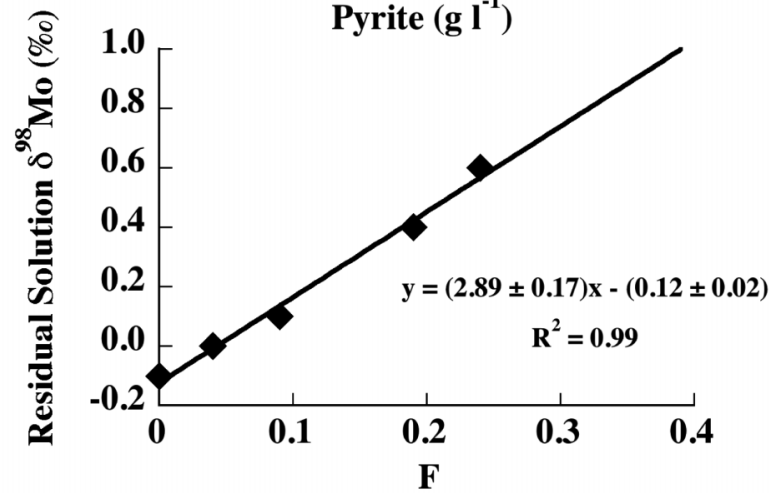

Fig. 2. (A) The amount of Mo adsorbed to pyrite plotted as a function of the amount of pyrite in solution as determined from Experimental Series A. The regression shows the line fit with the slope of $\sim 59 \mathrm{nmol} \mathrm{Mo} \mathrm{g}^{-1}$ pyrite. (B) The residual solution $\delta^{98} \mathrm{Mo}$ plotted as a function of the fraction of the Mo lost from solution during adsorption.

ple A5 was not successfully run for Mo isotopes), suggesting that the lighter Mo isotopes are preferentially adsorbed to the pyrite surface (Fig. 2B, Table 1). If we recast the data calculating $\mathrm{F}$ as the fraction of aqueous Mo adsorbed (e.g., [\% Mo Lost] in Table 1), the data are best fit by a linear regression $\left(R^{2}=0.99\right.$; Fig. $\left.2 \mathrm{~B}\right)$, suggesting that Mo is adsorbed to the pyrite surface with a constant fractionation of $\sim 2.9 \pm 0.1 \%$. Because of the difficulties associated with quantitatively recovering the pyrite from the filters, the pyrite-associated Mo was not analyzed and we are unable to confirm this fractionation by mass balance. Nevertheless, that the solution data all fall on a linear trend is consistent with the suggestion the Mo isotope fractionation associated with adsorption to pyrite is largely an equilibrium isotope effect. Similar equilibrium isotope behavior has been observed in previous Mo adsorption experiments (e.g., Barling and Anbar, 2004).

\section{Mo-sulfide precipitation}

Experiment Series 1-4 were conducted at higher aqueous Mo concentration $(\sim 100 \mu \mathrm{M})$ relative to Experiment Series A $(\sim 0.3 \mu \mathrm{M}$; Table 1). As with Experiment Series 
(A)

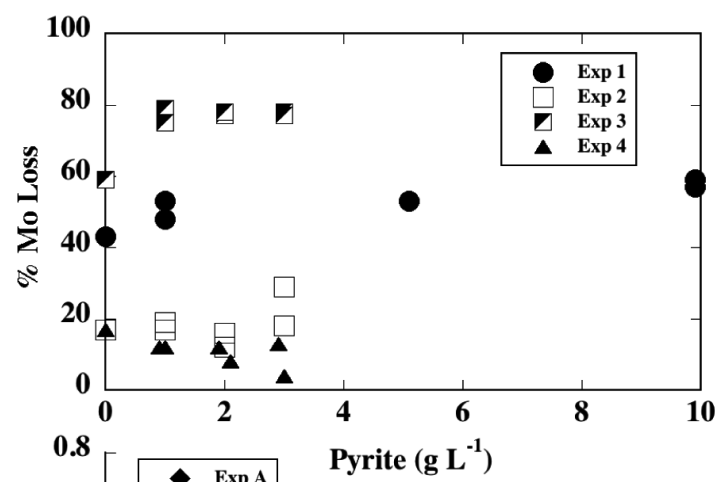

(B)

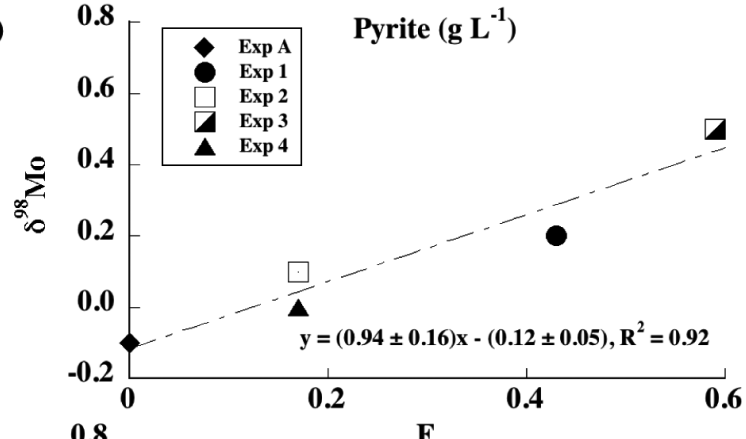

(C)

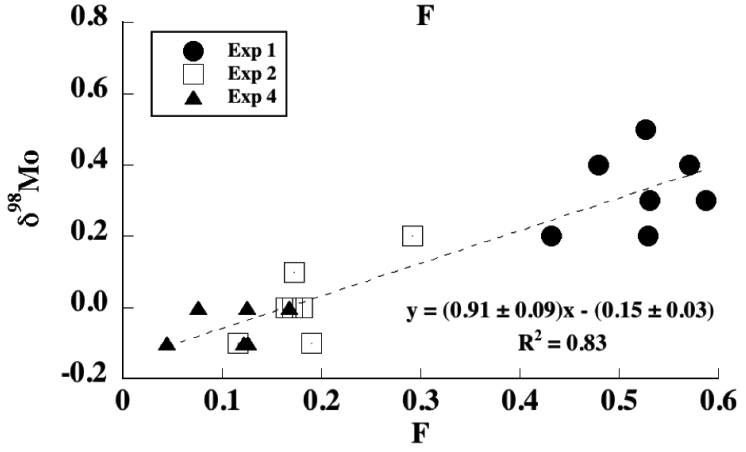

(D)

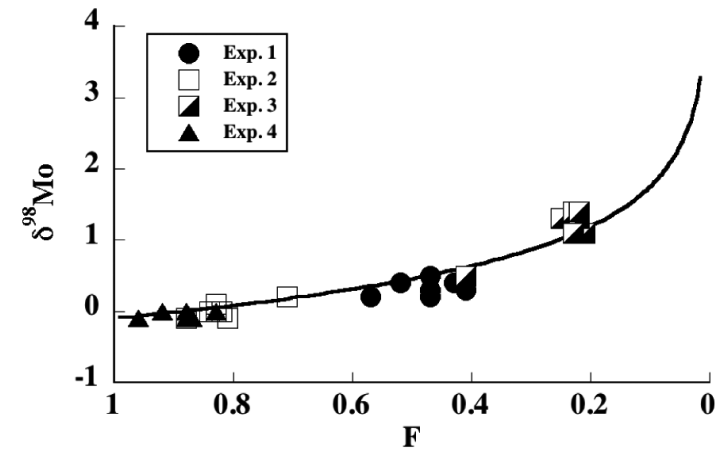

Fig. 3. (A) The $\%$ Mo loss plotted as a function of pyrite in solution. (B) The $\delta^{98}$ Mo for the experimental starting solutions for Experimental Series 1-4 and Experimental Series A as a function of the \% Mo Loss (precipitation). (C) $\delta^{98} M o$ data from Experimental Series 1,2, and 4 plotted as a function of total \% Mo Loss (precipitation or adsorption or both of these processes). (D) Same as in (C) but with values added from Experimental Series 3 and a Rayleigh-type curve to those data showing a fractionation of $0.8 \%$.
A, pyrite was reacted with the prepared experimental Mo solutions in Experiment Series 1-4, with the exception of the solutions used as controls for each experiment (labeled "START"; Table 1). If the relationship observed in Experiment Series A holds, and Mo adsorption is limited to $\sim 60 \mathrm{nmol} \mathrm{Mo/g} \mathrm{pyrite} \mathrm{(Fig.} \mathrm{2A),} \mathrm{it} \mathrm{is} \mathrm{possible} \mathrm{that}$ under these experimental conditions the maximum quantity of Mo adsorbed would be negligible with respect to the total amount of Mo in solution. For example, in Experiment Series 1 samples E and F, which have the highest pyrite suspension densities of any experimental run $(9.9 \mathrm{~g} / \mathrm{L}$; Table 1$)$, which would suggest that at most only $\sim 0.6 \mu \mathrm{M}$ Mo may have been adsorbed; less than $1 \%$ of the total initial Mo concentration (Table 1).

Despite the prediction of negligible Mo loss due to adsorption, all of the samples from Experiment Series 14 appear to have lost considerable dissolved Mo relative to the calculated initial concentrations, including the starting solutions that were never reacted with pyrite (Table 1, Fig. 3A). It thus appears that the increase in Mo concentration for these experiments (as compared to that of Experiment Series A) promoted significant Mo precipitation. Samples from the higher $\mathrm{pH}$ experiments showed less Mo removal, with the greatest quantity of Mo lost from solution at $\mathrm{pH} 4$ with added sulfide (Experiment Series 3; Fig. 3A, Table 1), where a dark-colored precipitate was visible in the bottles of filtered aqueous Mo samples. From the experimental control solutions never reacted with pyrite ("START" samples, Table 1) we can calculate the \% Mo Lost to precipitation (relative to the calculated initial Mo concentration from the known quantity of $\left(\mathrm{NH}_{4}\right)_{2} \mathrm{MoS}_{4}$ salt added; Table 1) and evaluate precipitation-controlled Mo isotope fractionation for these experiment series.

As seen in the adsorption results from Experiment Series A, the aqueous Mo solutions of the initial starting solutions from Experiment Series 1-4 become isotopically heavier with increasing Mo loss, regardless of the experimental conditions (e.g., $\mathrm{pH}$ and $\Sigma \mathrm{H}_{2} \mathrm{~S}$; Table 1). Recasting the data in terms of $\mathrm{F}$ as the fraction of aqueous Mo precipitated (e.g., [\% Mo Lost] in Table 1), the data are best fit by a linear regression $\left(R^{2}=0.92\right.$; Fig. 3B), suggesting a fractionation of $\sim 0.9 \pm 0.2 \%$ o between the aqueous solution and the solid-phase Mo.

Most pyrite-reacted samples from these experimental series have total estimated \% Mo Lost similar to the initial starting solutions, generally within $\sim 10 \%$ (Table 1 , Fig. 3A). The notable exception is Experiment Series 3, where samples reacted with pyrite appear to have lost $\sim 20 \%$ more Mo than the initial starting solution (Table 1, Fig. 3A). It appears that some additional process (perhaps adsorption to pyrite, perhaps a yet unidentified mechanism) has impacted the aqueous Mo concentrations of the samples from Experiment Series 3 that were re- 
acted with pyrite. Therefore, the data from these samples (Experiment Series 3A-F) are not used in further calculations regarding Mo precipitation.

For Experimental Series 1, 2, and 4, the similarity among the extent of Mo loss in the starting control solutions and those reacted with pyrite suggests that the same Mo precipitation process likely dominates Mo removal in all experimental samples, with adsorption to pyrite playing a minor role. It is worth noting, however, that the samples with the most Mo loss in a given experiment are typically those with the highest pyrite suspension densities (Table 1). This suggests that sorption to pyrite (while possibly a minor process) has presumably occurred in these experiments, and may still impact the measured Mo isotope compositions. However, if we set the specific details of the removal process aside and again recast samples from Experimental Series 1, 2, and 4 in terms of $F$ (e.g., [\% Mo Lost] in Table 1), the data are reasonably well-fit by a linear regression $\left(R^{2}=0.83\right.$; Fig. $\left.3 \mathrm{C}\right)$ that still predicts a fractionation of $\sim 0.9 \pm 0.1 \%$ o between the aqueous solution and the solid-phase Mo. We note here that this equilibrium modeling requires further validation, and should be treated as being equivocal at this point. If for example, we were to combine all the solutions, including those from Experimental Series 3, and treat those solutions as a closed system Rayleigh process, a similar offset could be obtained (Fig. 3D). Although there are a number of assumptions required for such a treatment, including that each of these experiments behaves the same, the salient point is that both approaches yield similar values and are both consistent with what we observe in the natural environment, which is in contrast to the Experimental Series A experiment.

\section{Discussion}

The adsorption-controlled Mo isotope fractionation observed in our Experiment Series A (2.9\%o) is much larger than that predicted from pore water samples in reducing sediments (e.g., see McManus et al., 2002) and the inferred seawater-reducing sediment fractionation predicted from observations at several continental margin sites $\left(\Delta^{98} \mathrm{Mo}_{\text {SW-SEDS }} \sim 0.7 \%\right.$; Poulson Brucker et al., 2009; Figs. 1B and C). Although we appreciate that Mopyrite interactions are indeed likely in these settings (Huerta-Diaz and Morse, 1992), the observed discrepancy between natural and experimental fractionations leads us to conclude that Mo adsorption to pyrite (as observed in these experiments) is not the dominant process responsible for Mo sequestration in continental margin sediments. The fractionation observed in the Mo-precipitation experiments $(\sim 0.9 \%)$, however, is more consistent with the average isotope fractionation associated with Mo burial in anoxic continental margin sediments (Poulson Brucker et al., 2009; Figs. 1B and C). This result suggests that a precipitation-like process (rather than a strict adsorption process) may be a more important control over Mo isotope compositions in these environments.

Regardless of the mechanism, it is clear from our experimental results that Mo isotope fractionation under reducing conditions could potentially produce Mo isotope values similar to those observed under more oxygenated conditions (e.g., Fig. 1C). Notably, the adsorption-controlled Mo isotope fractionation observed in our anoxic Experiment Series A (2.9\%o) is similar to the $2.7 \%$ o fractionation previously observed between soluble molybdate $\left(\mathrm{MoO}_{4}{ }^{2-}\right)$ and $\mathrm{Mo}$ adsorbed to $\mathrm{Mn}$-oxides under oxic conditions (Barling and Anbar, 2004; Wasylenki et al., 2008; Fig. 1C). Bostick et al. (2003) investigated adsorption of $\mathrm{MoS}_{4}{ }^{2-}$ to pyrite under anoxic conditions, and their results indicate that Mo forms inner-sphere complexes on $\mathrm{FeS}_{2}$. These authors identify the $\mathrm{MoS}_{4}{ }^{2-}$ adsorbed to pyrite as a $\mathrm{Mo}-\mathrm{Fe}-\mathrm{S}$ cubane, requiring significant rearrangement of the Mo structure relative to the tetrahedrally-coordinated $\mathrm{MoS}_{4}{ }^{2-}$ in solution. Similarly, Kashiwabara et al. (2011) attribute the magnitude of fractionation observed during Mo adsorption to $\mathrm{Mn}-$ oxides to formation of distorted inner-sphere complexes. It may be that when adsorption of aqueous Mo involves significant Mo restructuring and the formation of innersphere complexes, whether under oxic or anoxic conditions, the magnitude of the associated fractionation is the same. This observation potentially complicates the Mo isotope paleoproxy, as it means that the same Mo isotope fractionations could be generated under vastly different geochemical conditions.

\section{CONCLUSION}

$\mathrm{MoS}_{4}$ adsorption to pyrite appears to result in a large isotope fractionation $(2.9 \%$ ). This fractionation is roughly the same as that observed for $\mathrm{MoO}_{4}$ adsorption to manganese oxides (Barling and Anbar, 2004), although it differs from values obtained for $\mathrm{MoO}_{4}$ adsorption to a variety of iron oxides (Goldberg et al., 2009; Fig. 1C). The fractionation observed in our anoxic adsorption experiments is greater than that inferred for anoxic continental margin sediments, suggesting that adsorption to pyrite is not the sole process generating the isotopic compositions observed in reducing marine sediments. Instead, the Mo isotope fractionation we infer for Mo-sulfide precipitation is more in line with results from modern continental margin sediments (Poulson Brucker et al., 2009). We interpret our results to indicate that Mo adsorption to pyrite directly from an ocean water Mo reservoir is an inaccurate representation of the net authigenic process in reducing continental margin sediments. However, it is certainly plausible that the variations in sediment Mo iso- 
tope values observed in some reducing marine environments could result from a mixture of fractionation processes, including adsorption to pyrite.

Acknowledgments-Dr. Robert Collier kindly supplied his unpublished oxygen data along with his published Mo data. This research was funded by National Science Foundation grant OCE-0721102 to J.M. Any opinion, finding, conclusion, or recommendations expressed in this material are those of the authors and do not necessarily reflect the views of the National Science Foundation. Multiple reviewers provided helpful and constructive criticism on earlier versions of this manuscript, and we sincerely appreciate their efforts.

\section{REFERENCES}

Algeo, T. J. and Lyons, T. W. (2006) Mo-total organic carbon covariation in modern anoxic marine environments: Implications for analysis of paleoredox and paleohydrographic conditions. Paleoceanography 21, PA1016.

Anbar, A. D. and Rouxel, O. (2007) Metal stable isotopes in paleoceanography. Anu. Rev. Earth Planet. Sci. 35, 717.

Arnold, G. L., Anbar, A. D., Barling, J. and Lyons, T. W. (2004) Molybdenum isotope evidence for widespread anoxia in mid-Proterozoic oceans. Science 304, 87-90.

Barling, J. and Anbar, A. D. (2004) Molybdenum isotope fractionation during adsorption by manganese oxides. Earth Planet. Sci. Lett. 217, 315-329.

Barling, J., Arnold, G. L. and Anbar, A. D. (2001) Natural massdependent variations in the isotopic composition of molybdenum. Earth Planet. Sci. Lett. 193, 447-457.

Bertine, K. K. and Turekian, K. K. (1973) Molybdenum in Marine Deposits. Geochim. Cosmochim. Acta 37, 14151434.

Bostick, B. C., Fendorf, S. and Helz, G. R. (2003) Differential adsorption of molybdate and tetrathiomolybdate on pyrite $\left(\mathrm{FeS}_{2}\right)$. Environ. Sci. Technol. 37, 285-291.

Burdige, D. E. (2006) Geochemistry of Marine Sediments. Princeton University Press.

Calvert, S. E. and Pedersen, T. F. (1993) Geochemistry of recent oxic and anoxic marine sediments: Implications for the geological record. Mar. Geol. 113, 67-88.

Canfield, D. E. and Thamdrup, B. (2009) Towards a consistent classification scheme for geochemical environments, or, why we wish the term 'suboxic' would go away. Geobiology 7, 385-392, doi:10.1111/j.1472-4669.2009.00214.x.

Chappaz, A., Gobeil, C. and Tessier, A. (2008) Geochemical and anthropogenic enrichments of Mo in sediments from perenially oxic and seasonally anoxic lakes in Eastern Canada. Geochim. Cosmochim. Acta 72, 170-184.

Collier, R. W. (1985) Molybdenum in the Northeast Pacific Ocean. Limnol. Oceanogr. 30, 1351-1354.

Colodner, D. (1991) The marine geochemistry of rhenium, iridium, and platinum. Ph.D. Thesis, Woods Hole Oceanographic Institution Massachusetts Institute of Technology, WHOI-91-30.

Diaz, R. J. and Rosenberg, R. (2008) Spreading dead zones and consequences for marine ecosystems. Science 321, 926-929.
Dyrssen, D. W. (1999) Framvaren and the Black SeaSimilarities and differences. Aqua. Geochem. 5, 59-73.

Emerson, S. R. and Huested, S. S. (1991) Ocean anoxia and the concentrations of molybdenum and vanadium in seawater. Mar. Chem. 34, 177-196.

Erickson, B. E. and Helz, G. R. (2000) Molybdenum(VI) speciation in sulfidic waters: Stability and lability of thiomolybdates. Geochim. Cosmochim. Acta 64, 1149-1158.

Fossing, H. (1990) Sulfate reduction in shelf sediments in the upwelling region off Central Peru. Cont. Shelf Res. 10, 355367.

Goldberg, T., Archer, C., Vance, D. and Poulton, S. W. (2009) Mo isotope fractionation during adsorption to $\mathrm{Fe}$ (oxyhydr)oxides. Geochim. Cosmochim. Acta 73, 65026516.

Goldberg, T., Archer, C., Vance, D., Thamdrup, B., McAnena, A. and Poulton, S. W. (2012) Controls on Mo isotope fractionations in a Mn-rich anoxic mater sediment, Gullmar Fjord, Sweden. Chem. Geol. 296-297, 73-82.

Helz, G. R., Miller, C. V., Charnock, J. M., Mosselmans, J. F. W., Pattrick, R. A. D., Garner, C. D. and Vaughan, D. J. (1996) Mechanism of molybdenum removal from the sea and its concentration in black shales: EXAFS evidence. Geochim. Cosmochim. Acta 60, 3631-3642.

Helz, G. R., Vorlicek, T. P. and Kahn, M. D. (2004) Molybdenum scavenging by iron monosulfide. Environ. Sci. Technol. 38, 4263-4268.

Huerta-Diaz, M. A. and Morse, J. W. (1992) Pyritization of trace metals in anoxic marine sediments. Geochim. Cosmochim. Acta 56, 2681-2702.

Kashiwabara, T., Takahashi, Y. and Tanimizu, M. (2009) A XAFS study on the mechanism of isotopic fractionation of molybdenum during its adsorption on ferromanganese oxides. Geochem. J. 43, e31-e36.

Kashiwabara, T., Takahashi, Y., Tanimizu, M. and Usui, A. (2011) Molecular-scale mechanisms of distribution and isotopic fractionation of molybdenum between seawater and ferromanganese oxides. Geochim. Cosmochim. Acta, 75, 5762-5784.

Lyons, T. W., Anbar, A. D., Severmann, S., Scott, C. and Gill, B. (2009) Tracking euxina in the ancient ocean: A multiproxy perspective and proterozoic case study. Annu. Rev. Earth Planet. Sci. 37, 22.1-22.28.

McManus, J., Nägler, T. F., Siebert, C., Wheat, C. G. and Hammond, D. E. (2002) Oceanic molybdenum isotope fractionation: Diagenesis and hydrothermal ridge-flank alteration. Geochem. Geophys. Geosys. 3, $2002 \mathrm{GC} 000356$.

McManus, J., Berelson, W. M., Severmann, S., Poulson, R. L., Hammond, D. E., Klinkhammer, G. P. and Holm, C. (2006) Molybdenum and uranium geochemistry in continental margin sediments: Paleoproxy potential. Geochim. Cosmochim. Acta 70, 4643-4662.

Nägler, T. F., Neubert, N., Böttcher, M. E., Dellwig, O. and Schnetger, B. (2011) Molybdenum isotope fractionation in pelagic euxina: Evidence from the modern Black and Baltic Seas. Chem. Geol., 289, 1-11.

Neretin, L. N., Volkov, I. I., Böttcher, M. E. and Grinenko, V. A. (2001) A sulfur budget for the Black Sea anoxic zone. Deep-Sea Res. 48, 2569-2593. 
Neubert, N., Nägler, T. F. and Böttcher, M. E. (2008) Sulfidity controls molybdenum isotope fractionation into euxinic sediments: Evidence from the modern Black Sea. Geology 36, 775-778.

Poulson, R. L., Siebert, C., McManus, J. and Berelson, W. M. (2006) Authigenic molybdenum isotope signatures in marine sediments. Geology 34, 617-620.

Poulson Brucker, R. L., McManus, J., Severmann, S. and Berelson, W. M. (2009) Molybdenum behavior during early diagenesis: Insights from Mo isotopes. Geochem. Geophys. Geosys. 10, No. 6, doi:10.1029/2008GC002180.

Poulton, S. W. (2003) Sulfide oxidation and iron dissolution kinetics during the reaction of dissolved sulfide with ferrihydrite. Chem. Geol. 202, 79-94.

Scott, C., Lyons, T. W., Bekker, A., Shen, Y., Poulton, S. W., Chu, X. and Anbar, A. D. (2008) Tracing the stepwise oxygenation of the Proterozoic ocean. Nature 452, 456-459.

Scott, C., Bekker, A., Reinhard, C. T., Schnetger, B., Krapez, B., Rumble, D., III and Lyons, T. W. (2011) Late Archean euxinic conditions before the rise of atmospheric oxygen. Geology, 39, 119-122.

Severmann, S., McManus, J., Berelson, W. M. and Hammond, D. E. (2010) The continental shelf benthic iron flux and its isotope composition. Geochim. Cosmochim. Acta 74, 39844004

Siebert, C., Nägler, T. F. and Kramers, J. D. (2001) Determination of molybdenum isotope fractionation by double-spike multicollector inductively coupled plasma mass spectrometry. Geochem. Geophys. Geosys. 2, 2000GC000124.

Siebert, C., Nägler, T. F., von Blanckenburg, F. and Kramers, J. D. (2003) Molybdenum isotope records as a potential new proxy for paleoceanography. Earth Planet. Sci. Lett. 211, $159-171$.

Siebert, C., McManus, J., Bice, A., Poulson, R. L. and Berelson, W. M. (2006) Molybdenum isotope signatures in continen- tal margin marine sediments. Earth Planet. Sci. Lett. 241, 723-733.

Tribovillard, N., Riboulleau, A., Lyons, T. and Baudin, F. (2004) Enhanced trapping of molybdenum by sulfurized marine organic matter of marine origin in Mesozoic limestones and shales. Chem. Geol. 213, 385-401.

Tribovillard, N., Algeo, T. J., Lyons, T. and Riboulleau, A. (2006) Trace metals as paleoredox and paleoproductivity proxies: An update. Chem. Geol. 232, 12-32.

Vorlicek, T. P., Kahn, M. D., Kasuya, Y. and Helz, G. R. (2004) Capture of molybdenum in pyrite-forming sediments: Role of ligand-induced reduction by polysulfides. Geochim. Cosmochim. Acta 68, 547-556.

Wasylenki, L. E., Rolfe, B. A., Weeks, C. L., Spiro, T. G. and Anbar, A. D. (2008) Experimental investigation of the effects of temperature and ionic strength on Mo isotope fractionation during adsorption to manganese oxides. Geochim. Cosmochim. Acta, doi:10.1016/j.gca.2008.08.027. Wasylenki, L. E., Weeks, C. L., Bargar, J. R., Spiro, T. G., Hein, J. R. and Anbar, A. D. (2011) The molecular mechanism of Mo isotope fractionation during adsorption to birnessite. Geochim. Cosmochim. Acta 75, 5019-5031.

$\mathrm{Xu}, \mathrm{N}$., Christodoulatos, C. and Braida, W. (2006) Adsorption of molybdate and tetrathiomolybdate onto pyrite and goethite: Effect of $\mathrm{pH}$ and competitive ions. Chemosphere 62, 1726-1735.

Zheng, Y., Anderson, R. F., van Geen, A. and Kuwabara, J. (2000) Authigenic molybdenum formation in marine sediments: A link to pore water sulfide in the Santa Barbara Basin. Geochim. Cosmochim. Acta 64, 4165-4178.

\section{SUPPLEMENTARY MATERIALS}

URL (http://www.terrapub.co.jp/journals/GJ/archives/ data/46/MS167.pdf) 